\title{
Erratum to: On the Relation Between Solar Activity and Clear-Sky Terrestrial Irradiance
}

\author{
G. Feulner
}

Published online: 22 January 2013

(C) Springer Science+Business Media Dordrecht 2013

Erratum to: Solar Phys (2013) 282:615-627

DOI 10.1007/s11207-012-0129-z

While processing the article the Acknowledgements were mistakenly left out. Please find on this page the Acknowledgements that should be regarded as the final version by the reader.

Acknowledgements I would like to thank Ellsworth G. Dutton for providing me with the latest version of the Mauna Loa Observatory terrestrial solar irradiance data and for many helpful comments on these data. I am grateful to the anonymous referee for a thorough review. This research has made use of NASA's Astrophysics Data System Bibliographic Services.

The online version of the original article can be found under doi:10.1007/s11207-012-0129-z.

G. Feulner $(\varangle)$

Earth System Analysis, Potsdam Institute for Climate Impact Research (PIK), P.O. Box 601203 , 14412 Potsdam, Germany

e-mail: feulner@pik-potsdam.de 